\title{
EVALUATION OF ECONOMIC ASPECTS OF AERIAL TOPDRESSING
}

\author{
C. P. TEBB, Field Officer, N.Z. Meat and Wool Boards' Economic \\ Service, Hamilton
}

To begin with I would like to say a few words about the title of this paper. It is exactly as given to me by the Grassland Association, "Evaluation of Economic Aspects of Aerial Top-Dressing". It is not uncommon for the deliverer of a paper to be given a subject and then to select his own angle of that subject and title it accordingly. In fact, that is the more usual procedure, and of course could quite easily have been adopted by me in this instance.

Now I am not an economist, but as a field officer of the Meat and Wool Boards' Economic Service I am simply a person who is known to have quite a mass of information (mainly data) on hill country farming in the northern half of the North Island. You may be rather surprised then that I have breasted up to the rather difficult title of this paper, when perhaps I should be dealing more in the sphere of a simple and elastic title such as "Some Financial Aspects of Hill Country Topdressing".

However, I particularly wanted to adhere to the title as given me by the Grassland Association because it gives me the opportunity to highlight a certain fact right at the outset. That is this: today aerial topdressing hill country topdressing; the phrases are synonymous. Let me elaborate on that just a little. Aerial topdressing has been going now for ten years. For a start, there was often the comment, "It's too dear, I can't take that on." Or later, "I've tried it; it doesn't pay me." As the years have gone by, many articles, including one by myself, have been written showing the incidence of aerial topdressing; how much it cost here and how much there; how many farmers were topdressing by air in this year as compared with the other year; the number of airstrips here and the cost of airstrips there; and so on. It is my opinion that all that is now a thing of the past. We have moved on. Aerial topdressing is here, just as portable spray dipping and a host of other developments are. So that I am not going to spend any time at all dealing with the economics or cost of aerial topdressing as such or as opposed to any other kind of topdressing. As far as I am concerned this paper is about North Island hill country topdressing, which, as I see it, means aerial topdressing. The fact is, as this paper attempts to show, the level or coverage of topdressing necessary in the future to keep the hill country afloat, let alone 
progressing, is of such a dimension that only aerial application can ever cope with the bulk of it.

And so let me pass on to the job imposed. To try to evaluate the economics of topdressing on hill country is no simple matter. We know very well that fertiliser applications will make more herbage grow. Cuttings and weighings from plot trials can show this readily and this sort of work is being done all the time by the Department of Agriculture to assess the need for variations in manures used, trace element responses, optimum application rates, and so on. We know also quite well that introduction of clovers and improved grasses must go hand in hand with hill country topdressing in the initial stages. Manure is relatively wasted if applied to the native sward only, except in some favoured high rainfall areas where volunteer clovers appear to exist. Because of the relatively low inherent fertility of most hill country the results of topdressing and improvement of its pasture species are fairly slow and unspectacular at first: and we find that there are a thousand and one loopholes open for us to question the payability of manurial expenditure. In short, it is one thing to have a fully subdivided and equipped lowland farm, to start topdressing it, and to pinpoint the increased returns of say $£ 500$ as being directly attributable to the manurial expenditure of $£ 300$; but it is quite another thing to have ten to fifteen hundred acres of hill country divided into blocks varying from 20 to 200 acres, with some dark faces, some fern and scrub areas, and only 100 acres of improved pasture, to embark on a programme of topdressing with necessary overseeding and fencing, and then after some years try to relate the improved cash return to the topdressing expenditure. It cannot be done on simple low country lines, because of course an inseparable part of the improved return is obviously due to the complementary expenditures on fencing and seeds and a good many other things that are related to the snowballing effect of increased stocking.

However, I believe that I have adopted a method which can give a fair and reasonable evaluation of the economics of hill country topdressing. It involves studying the returns of a large number of properties over a term of years that were reasonably stable in the national economy sense and also free of those extreme seasonal forces which cause disruption to farm programmes. In such a study the properties are simply grouped according to their levels of topdressing coverage. A rejection is made of any property that brings new additional country into production. The point is that we know that aerial topdressing has made the bringing in of such land not only possible but very payable. To include such propositions in our study would be to weight the credit side unfairly. What we are concerned with is an evaluation of increased 
topdressing on existing productive hill country, with due allowance being made for the fact that the gradual improvement consequent upon the topdressing implies a need for other expenditure to raise the general physical status of the improvements on the property as we go along.

Table 1 represents the averaged analysis of a large number of figures taken from 39 hill country farms for the five-year period 1952-53 to 1956-57 inclusive. The reason I have taken those five years is in line with the point mentioned a minute ago. It was a period of good stable conditions; the general market returns for all stock and wool were more steady over this period than for a five-year term starting one year earlier or one year later.

Apart from a falling away of cattle values for six or seven months in the second half of 1956 there were no particular recessions and no droughts or occurrences to alter the even and upward trend of sheep and cattle farming progress. In short, it was the optimum five years for the progress, or utilisation at any rate, of hill country topdressing.

In column 1 are designated four large groups of farms. Every farm in every group is a true hill country property, having very little flat or wheel land; in short, all substantially aerial propositions. Second, none of these properties brought in extra land; the productive acreage remained constant from beginning to end. Third, these farms represent all the true hill country records available to me south of Auckland city, less rejections only for those properties that increased their productive area or made a complete and revolutionary change of stock policy. Since all the properties that I deal with were acquired by a statistical randomised selection for another purpose entirely, I feel it cannot be said that they were in any way specially selected to favour this thesis.

Finally, and of major importance to the validity of the study, all these 39 properties are old established ones as at 1952-53 and all had received either one or two years' aerial topdressing previously or else had topdressed at some reasonable pre-aerial level.

The group designations are explained as follows:

SAK $66 \%$ is a group of 21 South Auckland properties; total productive area 16,291 acres and lying in the counties of Raglan, Kawhia, Waikato, Waitomo, Taumarunui, Ohura, Kaitieke, and Waimarino. The percentage figure of $66 \%$ is the average annual coverage of topdressing made over those properties during those five years.

EC $60 \%$, EC $39 \%$ and EC 14\% represent a break-up of 19 East Coast properties; total productive area 47,454 acres and lying in the counties of Cook, Opotiki, Waikohu, Waiapu, and Wairoa. The percentages given for each group are the respective 
Hill Country Topdressing $1952-53$ to $1956-57$

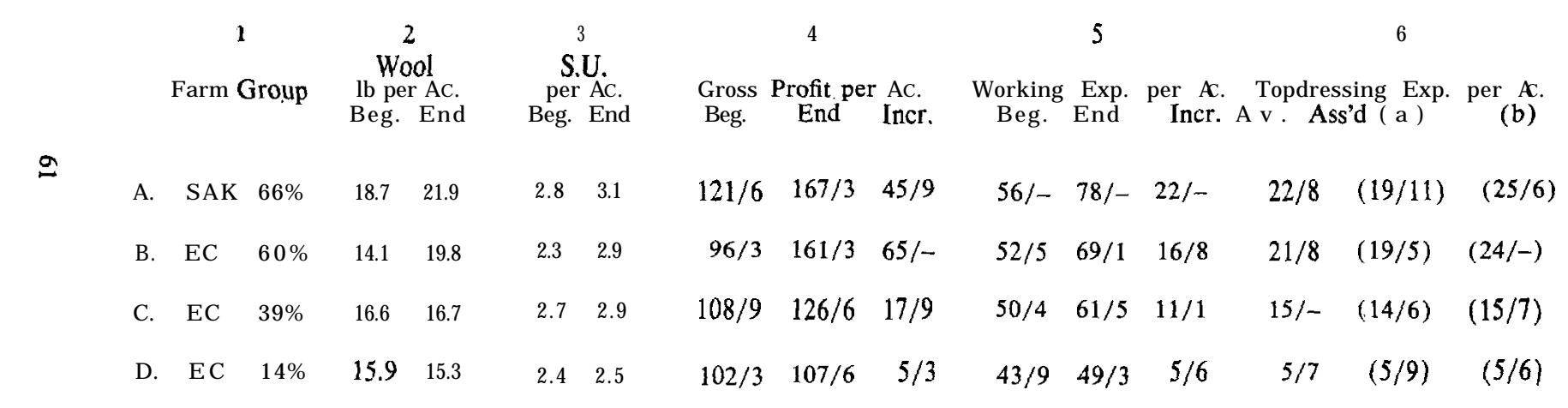


average annual coverage of topdressing made over those properties. In other words I divided up the East Coast properties into three groups, the consistent large area topdressers, the consistent medium area topdressers, and the inconsistent nil or occasional topdressers. The four groups are designated A, B, C, and D for ease of subsequent reference to them. It must be stressed that the individual farms in Groups $\mathrm{A}, \mathrm{B}$, and $\mathrm{C}$ did all topdress consistently. Only in Group D is there a mixture of farms topdressing erratically, with a maximum of 30 per cent in any year and in many instances omitting all topdressing in one or several years.

In column 2 the wool clip per acre at beginning and end is shown. I do not show the intermediate years, because I wish to keep the figures within reasonable bounds. In the A and B cases the increases were steadily progressive. In $\mathrm{C}$ and $\mathrm{D}$ the clips jumped up and down somewhat in the intermediate years. Note that the wool production increases of $\mathrm{A}$ and $\mathrm{B}$ are 17 per cent and 40 per cent, or a matter of 4 per cent and 10 per cent a year respectively, while $\mathrm{C}$ and $\mathrm{D}$ have remained stationary.

Column 3 shows the winter stocking rate in ewe equivalents (or stock units) per acre at beginning and end. The percentage increases over the five years are A 11, B 26, C 7, and D4: or annually A $2 \frac{3}{4}, \mathrm{~B} 63, \mathrm{C} 1 \frac{3}{4}, \mathrm{D} 1$. Now I realise that the ewe equivalent is a most unsatisfactory unit in many ways, especially on extensive country where considerable numbers of dry sheep and cattle exist. It is, of course, only a yardstick. In this particular instance, however, I consider it is of value in pointing out the fact that the South Auckland group (A), although comprising generally smaller farms, is very little more intensive than the East Coast groups.

As a matter of further interest, and because space did not permit in the main table, the break-down of stock units into sheep and cattle for each group is as follows:

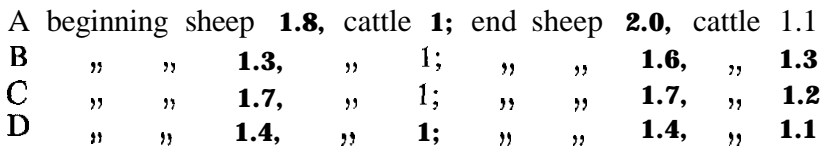

In all cases breeding ewes are near enough to 1 out of the total ewe equivalents. In the two top groups they are just under 1 at beginning and 1.1 at end actually. In the two bottom groups they are steady at 1 .

In column 4 there is the averaged gross return per acre at beginning, at end, and increase at end; in column 5 the total farm working expenditure is set out in the same way. It must be appreciated that these figures are not current, but for this present 
purpose they give a good basis for the comparisons being made in this paper.

Now I know very well that at the end a part of the increased gross return is due to enhanced market levels as opposed to pure increased output and a part of the increased expenditure is due to increased costs of goods and services as opposed to pure extra inputs. However, I propose not to confuse the issue with these factors, since, after all, for a comparative study of groups of similar farms over a fixed period of time, the plain cash figures are adequate. The farm working expenses in column 5 are the actual total operating expenses excluding the overheads of rent, interest, rates, taxes, insurance, and depreciation. Now many will say that these overheads should be included, as they are, so to speak, the very straw that often breaks the camel's back and puts the brake on topdressing (to mix a couple of metaphors). I agree that this is so, but all my effort is being directed toward showing that the factual physical expenditures on pastoral development of hill country do result in manifold increases in cash returns, if done at an adequate level.

In the final column (No. 6) is shown the averaged assessed expenditure per acre per annum on the actual topdressing. Firstly it must be emphasised that this figure is the total topdressing expenditure adapted to the whole farming area (just as expenses and returns are in columns 4 and 5). This column is not just the cost of topdressing per acre topdressed. Secondly, it is necessary to embark on some explanation of how these column 6 figures were arrived at. The fact is it is very difficult and often impossible to arrive at a pure inclusive figure for topdressing from a set of farm accounts; that is, for an outside person studying them some time after they were completed. It all depends on how the records -are kept. A typical difficulty is that some of the freights have become unidentifiable, for example. Anyway, it was my opinion in doing this work that the figures which I extracted and calculated for topdressing were more likely to be an understatement than otherwise. These "accounts extracted" figures are shown in brackets in the unheaded column no. 6 (a) and I have placed alongside them in unheaded column 6 (b) the results of a second calculation using what might be termed a blanket average cost of topdressing for South Auckland and for East Coast. In the case of the South Auckland group I did a lengthy treatise on this a year ago. I pointed out that during that period in that area $2 \frac{1}{2} \mathrm{cwt}$ of superphosphate was the general application rate and the extreme range of overall cost of manure, freights, and spreading lay between a maximum of $£ 18$ per ton in 1952 and a minimum of $£ 13$ per ton in 1957 . I settled on a fair average figure of $£ 1510$ s. per. ton, which at $2 \frac{1}{2} \mathrm{cwt}$ rate gives $38 \mathrm{~s}$. $9 \mathrm{~d}$. per acre topdressed. 
Adapted to the farming area a 66 per cent coverage of topdressing at $38 \mathrm{~s}$. 9d. gives a rate of $25 \mathrm{~s}$. $6 \mathrm{~d}$. an acre over the whole farm in that group. This is high and I must mention that most of these farms have now settled down to the 2 cwt rate anyway, which would bring them down to 20s. an acre these days if they are still maintaining the 66 per cent coverage. This $25 \mathrm{~s}$. $6 \mathrm{~d}$. is shown bracketed in the column 6 (b). My assessed column 6 figure is the mid-point between 19s. 1ld. and 25s. 6d., namely 22s. $8 \mathrm{~d}$.

Now in the East Coast the range of overall cost of superphosphate spread on the ground was to the best of my knowledge between the extremes of $£ 16$ and $£ 24$ a ton and still is. I have never made a detailed study in this area similar to that of my South Auckland farms. But I have seen a good many detailed statements of the total topdressing costs at different points and I have considered that for the purposes of this work E20 per ton spread would be a fair average figure for that five-year period over the groups B, C, and D. Two cwt at most is the usual application rate, making a cost of 40s. per acre topdressed. Adapted to the total farm acreages this gives the bracketed figures of $24 \mathrm{~s} ., 15 \mathrm{~s}$. $7 \mathrm{~d}$., and 5s. 6d. in the column 6 (b). These have been averaged with the 6 (a) figures to give the column 6 final assessed results of 21 s. $8 \mathrm{~d} ., 15 \mathrm{~s}$., and $5 \mathrm{~s} .7 \mathrm{~d}$.

Note that 6 (a) and 6 (b) figures are very similar in the low topdressing groups $\mathrm{C}$ and $\mathrm{D}$, but widen away from one another in the high topdressing groups $\mathrm{A}$ and $\mathrm{B}$, giving, I think, validity to my reasoning that my "accounts extractions" for topdressing were likely to be understated and needed boosting up.

Before leaving column 6 and the matter of the actual overall cost of topdressing I feel that I must refer to what seems to me to be an encouraging thing as regards the hill country. I believe it is often overlooked. We think in terms of the ever-increasing costs of goods and services and shake our heads in despair. I would draw your attention to the fact that in the main (I know there are exceptions) the total cost per ton of super-phosphate spread is no more now than it was in 1952-53. There are plenty of places (admittedly favourably sited) where it is very much lower. Now I think I can go as far as to say that there is no other farm operation or farm cost that that claim can be made for. On the East Coast the arrival of the Napier fertiliser works has gone a long way in helping to bring this about, but on the whole we have got to hand it to the rural aviation industry for their efficiency which has offset in large degree the rising cost of freights and labour and machinery; and, of course, to those many hill country farmers who have improved the incidence, siting, and condition of airstrips.

I think that the table shows a very clear case for continuous 
topdressing of hill country at a level of at least 50 per cent of the productive area. It indicates that a failure to topdress to a bold plan means standing still at the best, but more likely slipping back. In time-1 am not able to say when-no doubt fertility and carrying capacity will have been built up to a point where lower levels of topdressing will be sound; but until that time has been reached I would say that "catchpenny" small-scale topdressing of hill country is only payable in so far as it is applied for special benefits such as on a "topping-off" paddock or a lambing area or suchlike.

I would draw attention to the fact that if the topdressing expenditure is deducted from the operating costs, there is no colossal difference in the remaining working expenditure of these groups. The results of this subtraction are as follows:

At beginning A 33s. 4d., B 30s. 9d., C 35s. 4d., D 38s. 2 d.

At end A 55s. 4d., B 47s. 5d., C 46s. 5d., D 43s. 8d.

To me this implies that all these farms were being run very similarly all along, but the D group were virtually "just beating their wings" because of an inadequate manurial programme.

To put it another way, the increases in expenditure are extraordinarily similar to the amounts spent on topdressing; and the increases in gross returns almost ask to be designated on the following lines-Groups $\mathrm{A}$ and $\mathrm{B}$, progressive payable topdressing; Group C, bare maintenance level of topdressing; Group D, below maintenance level.

I seem to remember that around 1929 in lowland intensive paddock country, although we were using fertiliser with crops, of course, the whole question of using it on the grass paddocks was quite a moot point. Experiments were being done and fertiliser was being applied to grass here and there with a good deal of talk about whether or not it paid. During the ensuing ten or fifteen years improved pasture species, seed certification, and regular topdressing of virtually all good pastures on lowland paddock farms just swept ahead as we saw the light and came to regard pasture as a crop, which we were harvesting through our animals just as surely as we harvested our cereals through the threshing mill.

I cannot help thinking that our hill country farms-that is, more particularly, the extensive properties-are in 1959 in a similar relative position regarding topdressing and pasture to what our lowlands were in the late twenties. Now I do not mean that in a derogatory sense of being 30 years behind the times at all! I just mean that for three-quarters of that time, anyway, it has been physically impossible to pastorally improve other than 
relatively small selected patches of our hill country holdings by means of seed and fertilisers, but that during recent years the establishment of agricultural aviation has put the hill country man on a footing of actual ability to achieve widespread pastoral improvement. Of course the dice are loaded against him, as compared with the lowland farmer, initially at any rate, because, relatively, the costs are higher and the returns lower, and in most cases very much slower.

Nevertheless, I believe that the hill farmers' thinking has now got to pass beyond the point of fertilising small areas or condemning the cost of topdressing as too high. I believe that widespread pastoral improvement and continuous topdressing of hill country is essential. That of course is only echoing the remarks of Sir Bruce Levy in his talk at Massey Sheepfarmers' Conference last winter, but I feel that my figures may justify this.

The trouble with 'hill country is basically that much of it will and does run along without topdressing. The topdressing item is used as the safety valve for covering contingencies such as sudden falls in seasonal returns and unexpected obligations to the Inland Revenue Department. The last ten years have seen the application of fertiliser to hill country grow from virtually nothing to 400,000 tons a year. Over much of this period there was the benefit of the wool retention moneys and good prices for wool and stock which provided finance for this major revolution in the hill country sector of our farming. Now during the past two seasons there is evidence that quite a proportion of our hill country farmers have tended to curtail their topdressing under pressure of lower prices and a change in taxation system. They have had recourse to the safety valve and in doing so have probably lessened the payability of their existing topdressing programme, apart from retarding their progress.

I think that expenditure on hill country topdressing must be given a new look in some way. I would suggest it must come to be looked upon as a fixed overhead. A rational attitude to be adopted by the hill country farmer and those associated with him should perhaps be to fix on a certain minimum level of annual topdressing, according to some formula which might become widely .known and accepted in a given area, not just merely by other farmers, but by bank managers, mortgagees, and politicians too! The sort of thing I mean is a simplified minimum prescription such as half a hundredweight per breeding ewe or something like that.

I suppose 1 had better safeguard myself by adding that I am not recommending that fertiliser be just thrown on at a certain level regardless. Obviously it must be applied to a plan on selected areas which are also grazed to a plan. I think I would be right in 
saying on almost any hill country that such selected areas must be treated continuously for several years running before it is either pastorally or economically sound to ease off them in favour of another.

To conclude: this paper has given some results on a very general averaged plane. But I think maybe therein lies such strength as it has, because scepticism is more easily aroused against phenomenally impressive single examples than against a mass of less spectacular evidence. 